\title{
V3 versican isoform expression has a dual role in human melanoma tumor growth and metastasis
}

\author{
Laia Miquel-Serra ${ }^{1}$, Montserrat Serra ${ }^{1}$, Daniel Hernández ${ }^{1}$, Clelia Domenzain ${ }^{1}$, \\ María José Docampo ${ }^{1}$, Rosa $\mathrm{M} \mathrm{Rabanal}^{2}$, Inés de Torres ${ }^{3}$, Thomas $\mathrm{N} \mathrm{Wight}^{4}$, \\ Angels Fabra ${ }^{5}$ and Anna Bassols ${ }^{1}$
}

\begin{abstract}
${ }^{1}$ Facultat de Veterinària, Departament de Bioquímica i Biologia Molecular, Universitat Autònoma de Barcelona, Bellaterra, Spain; ${ }^{2}$ Facultat de Veterinària, Departament de Medicina i Cirurgia Animals, Universitat Autònoma de Barcelona, Bellaterra, Spain; ${ }^{3}$ Servei Anatomia Patològica, Hospital Vall d'Hebron, Barcelona, Spain; ${ }^{4}$ The Hope Heart Program, Benaroya Research Institute at Virginia Mason, Seattle, WA, USA and ${ }^{5}$ Institut de Recerca Oncologica, L'Hospitalet de Llobregat, Spain
\end{abstract}

\begin{abstract}
Versican is a large chondroitin sulfate proteoglycan produced by several tumor cell types, including malignant melanoma, which exists as four different splice variants. The presence of versican in the extracellular matrix plays a role in tumor cell growth, adhesion and migration, which could be altered by altering the ratio between versican isoforms. We have previously shown that overexpression of the V3 isoform of versican in human melanoma cell lines markedly reduces cell growth in vitro and in vivo, since V3-overexpressing (LV3SN) cultured cells as well as primary tumors arising from these cells grow slower than their vector-only counterparts (LXSN). In the present work, we have extended these observations to demonstrate that the delayed cell growth is due to multiple events since differences in proliferative index as well as in apoptosis are observed in LV3SN cells and tumors compared to LXSN. For example, LV3SN melanoma cells exhibit delayed activation of MAPK in response to EGF, we have also characterized further the primary tumors originated in nude mice from V3-transduced melanoma cells to determine if other events affect the V3 tumor phenotype. For example, hyaluronan content of LV3SN tumors was higher than in LXSN tumors, whereas other related matrix components and vascularization were unaffected. Furthermore, lung metastasis in nude mice occurred only in animals carrying LV3SN tumors, indicating a dual role for this molecule, both as an inhibitor of tumor growth and a metastasis inductor.
\end{abstract}

Laboratory Investigation (2006) 86, 889-901. doi:10.1038/labinvest.3700449; published online 17 July 2006

Keywords: hyaluronan; melanoma; metastasis; proteoglycan; tumorigenesis; versican

Tumor growth regulation by extracellular matrix components has been one of the main topics on tumor biology in the last years. Proteoglycans from the hyalectan family such as versican together with hyaluronan surround cells and alter cell proliferation, adhesion and migration, through one or more of the hyaluronan cell membrane receptors, such as CD44. ${ }^{1,2}$ Versican is highly expressed in fast growing tissues and cells, such as during embryogenesis and in many tumors, and it has been suggested that it plays a direct role in cell proliferation and other cell

Correspondence: Dr A Bassols, PhD, Facultat de Veterinària, Departament de Bioquímica i Biologia Molecular, Universitat Autònoma de Barcelona, 08193 Bellaterra, Spain.

E-mail: anna.bassols@uab.es

Received 9 February 2006; revised 31 May 2006; accepted 3 June 2006; published online 17 July 2006 functions. ${ }^{3}$ Versican, as well as the other members of the hyalectan family, has three structural domains: the N-terminal region (G1 domain) is responsible for binding hyaluronan: the central domain carries the glycosaminoglycan chains and the C-terminal globular region (G3 domain) interacts with simple carbohydrates, glycosaminoglycans (GAG) and with other proteins such as tenascin. ${ }^{1,4-6}$ The central domain of versican consists of two large subdomains, designated GAG- $\alpha$ and GAG- $\beta$ that are encoded by two alternatively spliced exons. In mammals, versican appears as four possible spliced variants: V0 is the largest one and contains both GAG- $\alpha$ and GAG- $\beta$ subdomains; V1 contains GAG- $\beta$, V2 contains GAG- $\alpha$ and V3 lacks any GAG subdomain. ${ }^{4,7}$ Versican isoforms differ in the size of the GAG subdomain and, subsequently, in the number of covalently bound GAG chains and the existing 
distance between G1 and G3 subdomains. Thus, the smallest splice variant V3 consists only of the amino and carboxy-terminal globular domains of versican and, therefore, retains many of the binding properties of versican, but lacks chondroitin sulfate chains and the high charge density and size of the large versican isoforms.

Our group has described a marked production of the large isoforms of versican $\mathrm{V} 0$ and $\mathrm{V} 1$ in malignant melanoma, contributing to the increased cell proliferation rate and decreased cell adhesion in these tumor cells. ${ }^{8,9}$ Overproduction of versican is a common feature of several tumor types and it is usually related to poor prognosis, as in the case of prostate cancer, ${ }^{10-12}$ breast cancer, ${ }^{13-15}$ or histiocytoma. ${ }^{16}$ Versican has been postulated to contribute to the proliferative, adhesive and migratory state of tumor cells, as well as an important modulator of tumor cell attachment to the interstitial stromal matrix of the tumor. We have recently described that overexpression of the short V3 versican isoform in melanoma cells decreases cell proliferation, increases cell adhesion on hyaluronan and enhances the ability to migrate on hyaluronan-coated transwell chambers through a CD44-mediated mechanism. In vivo, tumors arising in nude mice from V3-overexpressing melanoma cells grow slower than control tumors, indicating that the short V3 isoform of versican that lacks chondroitin sulfate chains could reverse the malignant phenotype of melanoma cells. ${ }^{17}$ This result was similar to that reported in vascular smooth muscle cells overexpressing the V3 isoform, which present an increased adhesion and diminished potential for proliferation and migration than control cells, ${ }^{18}$ raising the possibility that V3 isoform could exert its effects through changes in the pericellular coat by competing with the larger chondroitin sulfate-bearing V0 and V1 isoforms of versican. Nevertheless, a direct effect of V3 isoform independent of the presence of the large isoforms should exist in melanoma cells, since the effects could be observed in V0/V1 lacking cell lines, as the human MeWo or the canine CML10c2 melanoma cell lines.

In the present work, we have characterized the primary V3-overexpressing tumors originated from MeWo human melanoma cells, and describe the ability of V3-overexpression to increase the metastatic potential of melanoma cells, despite its negative effect on primary cell growth.

\section{Materials and methods}

\section{Cell Culture}

Human melanoma MeWo cell line originally derived from a human melanoma by Houghton et al ${ }^{19}$ was obtained from Dr FX Real (IMIM, Barcelona, Spain). CML-10c2 canine melanoma cells were obtained from Dr EG MacEwen (University of Wisconsin, WI, USA). ${ }^{20,21}$ Cells were grown in a humidified atmosphere at $37^{\circ} \mathrm{C}$ with $5 \% \mathrm{CO}_{2}$ in DMEM medium supplemented with $10 \%$ fetal calf serum, $100 \mathrm{IU} / \mathrm{ml}$ penicillin and $100 \mu \mathrm{g} / \mathrm{ml}$ streptomycin (all from GibcoBRL/Life Technologies, Rockville, MD, USA).

\section{Retroviral Vector Construction and Infection}

The retroviral vector containing the V3 gene (LV3SN) as well as the empty control vector (LXSN) were prepared as previously described. ${ }^{22}$ Both vectors were used to infect MeWo human melanoma cell lines using PA317 cells as described. ${ }^{18}$

\section{Antibodies}

The polyclonal antiversican antibody was raised in rabbits in our laboratory, against versican purified from conditioned medium from human U251 astrocytoma cells. ${ }^{8}$ The antibody recognized the protein core of versican, but it was unable to detect the whole chondroitin sulfate-bearing proteoglycan form in Western blot as well as in immunocytochemistry. ${ }^{8}$

Anti-human CD44 used for immunohistochemistry was kindly provided by Dr R Vilella (Hospital Clinic de Barcelona, Spain). The antibodies against MAPK and phospho-MAPK were from Cell Signaling Technology and kindly provided by Dr Néstor Gòmez (Dept. Bioquímica i Biologia Molecular, UAB, Spain). Antibodies against $\alpha v$ and $\beta 1$ integrins (clone 17E6 and clone P4C10, respectively), and against CD31 (clone MEC 13.3, BD PharMingen, Canada) were kindly given by Dr F Mitjans, (Merck $\mathrm{I}+\mathrm{D}$, Barcelona, Spain). A list of the antibodies used in this work is given in Table 1.

\section{Epidermal Growth Factor Treatment and MAPK Analysis}

MeWo cells were cultured in serum-free medium for 48 or 144 hours. At these proliferation times, EGF (25 ng/ml, Sigma) was added and cells were incubated for different times (0, 2, 5, 10, 20 and $30 \mathrm{~min})$. For MAPK analysis, cell extracts were prepared in $1 \%$ Triton X-100, $1 \mathrm{mM}$ EDTA, $1 \mathrm{mM}$ EGTA, $1 \mathrm{mM}$ $\mathrm{NaVO}_{4}, 10 \mathrm{mM}$ sodium glycerophosphate, $50 \mathrm{mM}$ $\mathrm{NaF}, 5 \mathrm{mM}$ sodium pyrophosphate, $0.27 \mathrm{mM}$ sucrose, $50 \mathrm{mM}$ Tris-HCl pH 7.5, $0.5 \mathrm{mM}$ benzamidine, $0.1 \% \beta$-mercaptoethanol, $25 \mathrm{mM}$ PMSF. The amount of protein applied to the gels was normalized after Bradford quantification. Samples were analyzed in a $10 \%$ polyacrylamide gradient gel, as described by Laemmli. ${ }^{23}$ After electrophoresis, proteins were transferred onto Immobilon-P membranes (Millipore Corp., Bedford, MA, USA). The blot was placed in a blocking solution consisting of $5 \%$ skim milk in Tris-buffer-saline (TBS), $0.05 \%$ Tween-20 and incubated for $1 \mathrm{~h}$ at room temperature. The membranes were incubated with the primary antibody in $5 \%$ skim milk in $0.05 \%$ Tween-20-TBS, for 
Table 1 Antibodies used for staining

\begin{tabular}{|c|c|c|c|c|}
\hline Detection & Section & Blocking reagent & Primary antibody & Dilution \\
\hline Versican & Paraffin & $\mathrm{NGS}^{\mathrm{a}}$ & Rabbit anti-versican ${ }^{\mathrm{b}}$ & $1: 50$ \\
\hline CD44 & Paraffin & MOM Reagent & $\mathrm{mAb}$ anti-CD44 ${ }^{\mathrm{c}}$ & 1:10 \\
\hline Ki67 & Paraffin & Serum & $\mathrm{mAb}$ anti-Ki67 ${ }^{\mathrm{d}}$ & $1: 200$ \\
\hline CD31 & Frozen & $\mathrm{NRS}^{\mathrm{a}}$ & Rat anti-CD31 ${ }^{\mathrm{e}}$ & $1: 200$ \\
\hline$\alpha v$ & Frozen & MOM Reagent & $\mathrm{mAb}$ anti- $\alpha v^{\mathrm{f}}$ & $1: 50$ \\
\hline$\beta 1$ & Frozen & MOM Reagent & $\mathrm{mAb}$ anti- $\beta 1^{\mathrm{g}}$ & $1: 50$ \\
\hline MT1-MMP & Paraffin & $\mathrm{NGS}^{\mathrm{a}}$ & mAb anti-MT1-MMP & $1: 25$ \\
\hline MMP-9 & Paraffin & $\mathrm{NGS}^{\mathrm{a}}$ & mAb anti-MMPgi & $1: 50$ \\
\hline MMP-2 & Paraffin & $\mathrm{NGS}^{\mathrm{a}}$ & mAb anti-MMP2 $2^{j}$ & $1: 25$ \\
\hline
\end{tabular}

${ }^{\mathrm{a}} \mathrm{NGS} / \mathrm{NRS}$ : normal goat serum/normal rabbit serum.

${ }^{\mathrm{b}}$ Antibody raised in our laboratory (Touab et $a l^{8}$ ).

c 156-3C11, kindly given by Dr R Vilella (Hospital Clínic, Barcelona, Spain).

${ }^{\mathrm{d}}$ DakoCytomation, Denmark.

${ }^{\mathrm{e}}$ MEC 13,3 (BD Pharmingen, Canada).

f,g17E6 and P4C10, respectively, kindly given by Dr F Mitjans (Merck I+D, Barcelona, Spain).

${ }_{h, i, j}$ Calbiochem (San Diego, CA, USA).

$16 \mathrm{~h}$ at $4^{\circ} \mathrm{C}$, washed, incubated with an anti-mouse secondary antibody labeled with peroxidase and visualized by chemiluminiscence (ECL System, Amersham Bioscience, Uppsala, Sweden).

\section{Cell Viability Studies}

LXSN and LV3SN MeWo melanoma cells were seeded at $16 \times 10^{4}$ cells/plate and incubated for 72 , 96, 120 and $144 \mathrm{~h}$. After incubation, cells present in the conditioned medium and cells attached to the plate were collected, stained with Trypan blue and counted.

\section{Tumor Growth in Nude Mice}

LXSN and LV3SN cells $\left(1 \times 10^{6}\right.$ cells in $100 \mu$ l of PBS) were injected intradermally into the flank of $\mathrm{BALB} / \mathrm{C} n u / n u$ nude mice (a total of four animals per cell line, two injection sites per animal). Animals were monitored by visual inspection until the tumor size was $\geq 0.5 \mathrm{~cm}$. At that time, primary cutaneous tumors were excised and divided in two parts: one part was fixed in $10 \%$ formalin and embedded in paraffin wax; the other half was included in OCT and frozen in liquid nitrogen. Sections $(4 \mu \mathrm{m})$ of the paraffin and frozen blocks were cut and stained by routine methods with hematoxylin and eosin (HE) for histopathological evaluation. Total number of mitotic cells in tumors was evaluated microscopically by counting stained nuclei in metaphase or anaphase vs total number of cells.

For the study of spontaneous metastasis, mice were maintained after surgically excising the primary tumors until appearance of indicative symptoms. Mice were euthanized and the necropsy performed to identify the location and perform the histological characterization of metastasis.

\section{Immunohistochemistry}

For detection of versican, CD44, Ki67, MMP-2, MMP-9 and MT1-MMP, sections were deparaffinized using standard procedures. CD31 and both $\alpha v$ and $\beta 1$ integrins expression were investigated on frozen sections. In all specimens, the endogenous peroxidase was inhibited by treating the sections with $3 \% \mathrm{H}_{2} \mathrm{O}_{2}$ in methanol for $30 \mathrm{~min}$. Blocking was performed with $20 \%$ normal serum, depending on the source of the secondary antibody, for $1 \mathrm{~h}$. For the monoclonal antibodies raised in mice (CD44, $\alpha v$ and $\beta 1$ integrin), a step consisting in blocking with MOM reagent (Mouse on-mouse, Vector laboratories, Burlingame, CA, USA) was used to avoid interfering background due to binding of endogenous mouse antibody. Sections were incubated with the primary antibody (see Table 1) at $4^{\circ} \mathrm{C}$ overnight. After washing several times, they were incubated with a secondary antibody for $1 \mathrm{~h}$ at room temperature. Avidin-biotin (ABC) complex (Vector Laboratories) and $3-3^{\prime}$-diaminobenzidine tetrahydrocloride (DAB) were used as the detection system. The samples were counterstained with Mayer's hematoxylin solution. In all negative controls, a preimmune serum was used instead of the primary antibody.

For histological detection of hyaluronan (HA), a biotinylated hyaluronan binding protein (bHABP) derived from cartilage (Seikagaku Ltd., Tokyo, Japan) was used on deparaffinized sections. Negative controls were digested with $20 \mu \mathrm{U} / \mathrm{ml}$ hyaluronidase in $50 \mathrm{mM}$ sodium acetate, $0.15 \mathrm{M} \mathrm{NaCl} \mathrm{pH}$ 6.7 at $37^{\circ} \mathrm{C}$ for $1 \mathrm{~h}$. Sections were incubated in parallel with the same solution without enzyme. After washing with PBS, all samples were blocked for $30 \mathrm{~min}$ with $10 \%$ normal goat serum. After blocking, specimens were overlaid with $5 \mu \mathrm{g} / \mathrm{ml}$ of bHABP in PBS- $0.1 \%$ BSA overnight at $4^{\circ} \mathrm{C}$. Sections were washed with $\mathrm{PBS}$ and the reaction was detected with the ABC complex (Vector Laboratories) at $1 / 50$ dilution for $30 \mathrm{~min}$, and visualized 
with DAB containing $0.035 \% \mathrm{H}_{2} \mathrm{O}_{2}$ for $10 \mathrm{~min}$ at $37^{\circ} \mathrm{C}$. Nuclei were counterstained with Mayer's hematoxylin solution.

In all cases, high-power light-microscopic images were digitally captured using a Nikon Eclipse E800 epifluorescence microscope with an integrated camera system.

\section{Measurements of Vessel Density}

Vessels stained by antibodies against CD31 were counted by the Chalkley counting procedure. ${ }^{24}$ A 25 point Chalkley eyepiece graticule, which contains 25 randomly positioned dots, was applied to the ocular of the microscope. At $\times 100$ magnification, this graticule is rotated so the maximum of the points are on or within the vessels of the vascular hot spots (areas of the tumor containing the maximum number of vessels) and the overlying dots are counted. From each section 10 areas of the tumor were studied.

\section{TUNEL Reaction and Hoechst Staining for Apoptosis Detection in Primary Tumors}

For TUNEL apoptotic cell detection, deparaffinized samples were labelled with Terminal deoxynucleotidyl Transferase (TdT) following the protocol of the In situ Cell Death Detection Kit (Roche).

For Hoechst staining, sections were deparaffinized using standard protocols. After rinsing in PBS, sections were permeabilized with $0.5 \%$ Triton X-100 in PBS for $15 \mathrm{~min}$ and washed two times in PBS. Sections were then incubated for $2 \mathrm{~h}$ with Hoechst $33342(2 \mu \mathrm{g} / \mathrm{ml}$, Sigma). Subsequently, sections were washed in $\mathrm{H}_{2} \mathrm{O}$ and mounted in a mounting medium for fluorescence (Vectashield ${ }^{\mathbb{R}}$, Vector Laboratories Inc.). Slides were visualized with a Nikon Eclipse E800 epifluorescence microscope and photographed with an integrated camera system.

\section{Statistical Analysis}

Data for each experimental group were compared using Welch's $t$-test using the free statistical programming environment $\mathrm{R}$. The level of significance was fixed at $P<0.05$.

\section{Results}

\section{Cell Proliferation and Apoptotic Rate in LXSN and LV3SN Melanoma Cells and Derived Tumors}

Our group has previously described that tumor growth from LV3SN MeWo cells was slower than from LXSN cells, indicating that V3-overexpression limited the tumorigenic potential of melanoma cells in vivo. ${ }^{17}$ The morphology of tumor cells was similar in LXSN and LV3SN tumors in all the cases. A small number of inflammatory cells was observed in both tumor types. All tumors were markedly necrotic, but no main differences in the total affected area were observed. As there were not morphological differences between tumors arising from LXSN and LV3SN cells, we have analyzed the mitotic and apoptotic activity of tumor cells, as well as the expression of several extracellular matrix components in order to find an explanation of the diminished tumorigenic potential of V3-overexpressing cells.

A significant difference in mitotic index was observed amongst primary tumors. The LXSNderived tumors exhibited a significantly higher mitotic index (Figure 1a). Correspondingly, the nuclear proliferative marker Ki67 was analyzed in MeWo LXSN-derived and LV3SN-derived tumors (Figure $1 \mathrm{~b}$ and $\mathrm{c}$ ). The proliferative marker Ki67 and the mitotic index were significantly higher in LXSN tumors $(P<0.0001$ for both mitotic index and Ki67 antigen). Therefore, differences in cell proliferation potential are important factors for the delayed growth of LV3SN tumors.

Furthermore, we analyzed the apoptotic index of LXSN-derived and LV3SN-derived tumors. Staining with the nuclear reagent Hoechst 33342 that allows the visualization of apoptotic cells characterized by brightly stained nuclei with lobular morphology indicated that LV3SN tumors contained more apoptotic cells (Figure 2a and b). A TUNEL assay showed an increase in the number of apoptotic cells in LV3SN tumors (Figure 2c). The total number of apoptotic cells was counted under the microscope and estimated as 127 apoptotic cells $/ \mathrm{cm}^{2}$ in LXSN tumors, and 247 apoptotic cells/ $\mathrm{cm}^{2}$ in LV3SNderived tumors. By both methods, the difference between LXSN and LV3SN cells was statistically significant $(P<0.001$ for Hoechst; $P<0.01$ for TUNEL assay).

These results were similar to those observed in vitro, since MeWo LV3SN cells grow slower than the corresponding LXSN cells. ${ }^{17}$ When looking for a mechanism to explain this behavior, the possibility that V3 overexpressing cells could respond differently to the mitogenic effect of growth factors such as EGF was considered since it is has been described that versican can interact with the EGF receptor through its G3 domain. ${ }^{25,26}$ To test this hypothesis, LXSN and LV3SN MeWo cells were treated with EGF, and the activation of the MAPK pathway was assessed by Western blot of the phosphorylated and total MAPK forms. As can be observed in Figure 3, a delay in the activation of the MAPK can be detected in LV3SN MeWo cells, both in recently seeded cells (48 $\mathrm{h}$ after seeding) as well as in long term cultures (144 $\mathrm{h}$ after seeding, not shown).

To analyze whether there was a correspondence between in vivo and in vitro results regarding cell death, we directly counted the number of dead unattached cells in LXSN and LV3SN cells. The percentage of dead cells in LV3SN MeWo cells was higher than in control cells (1.5 vs $0.5 \%$ ), although 
a
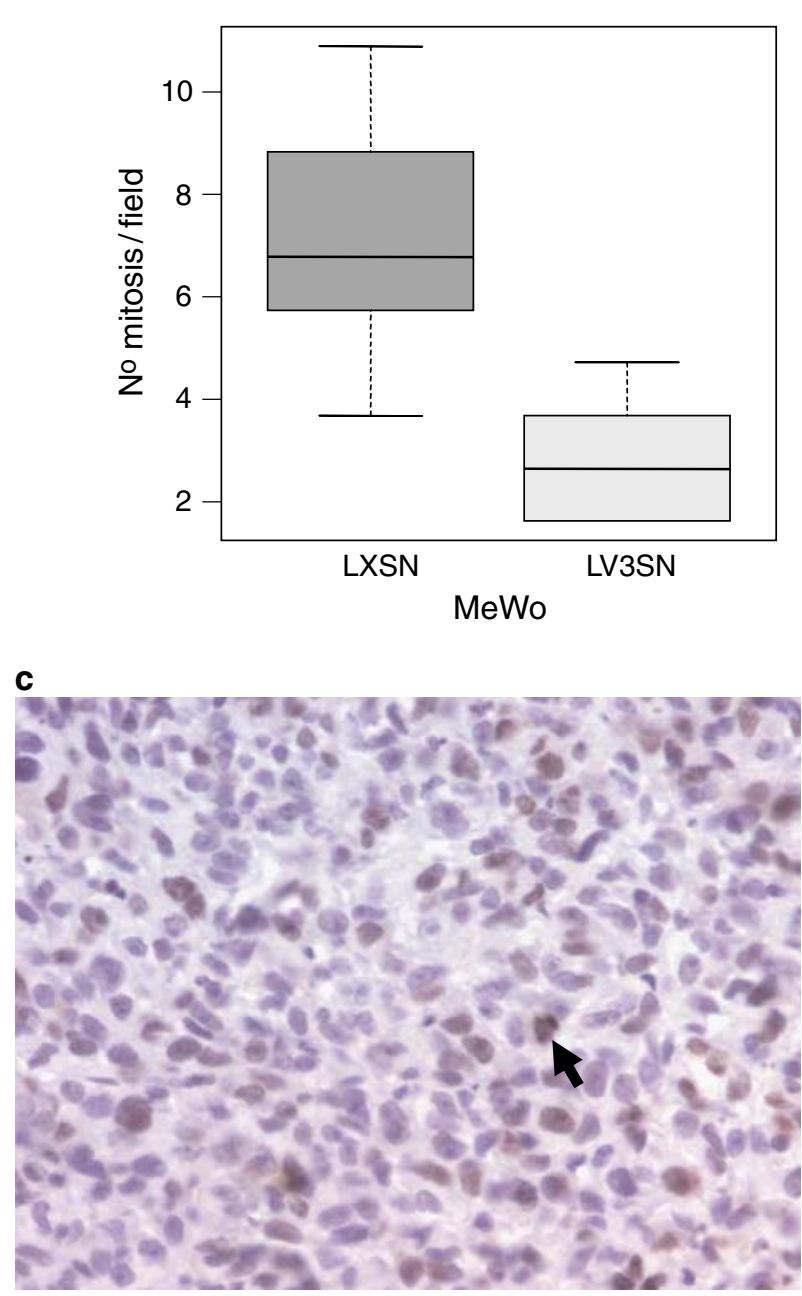

MeWo LXSN b
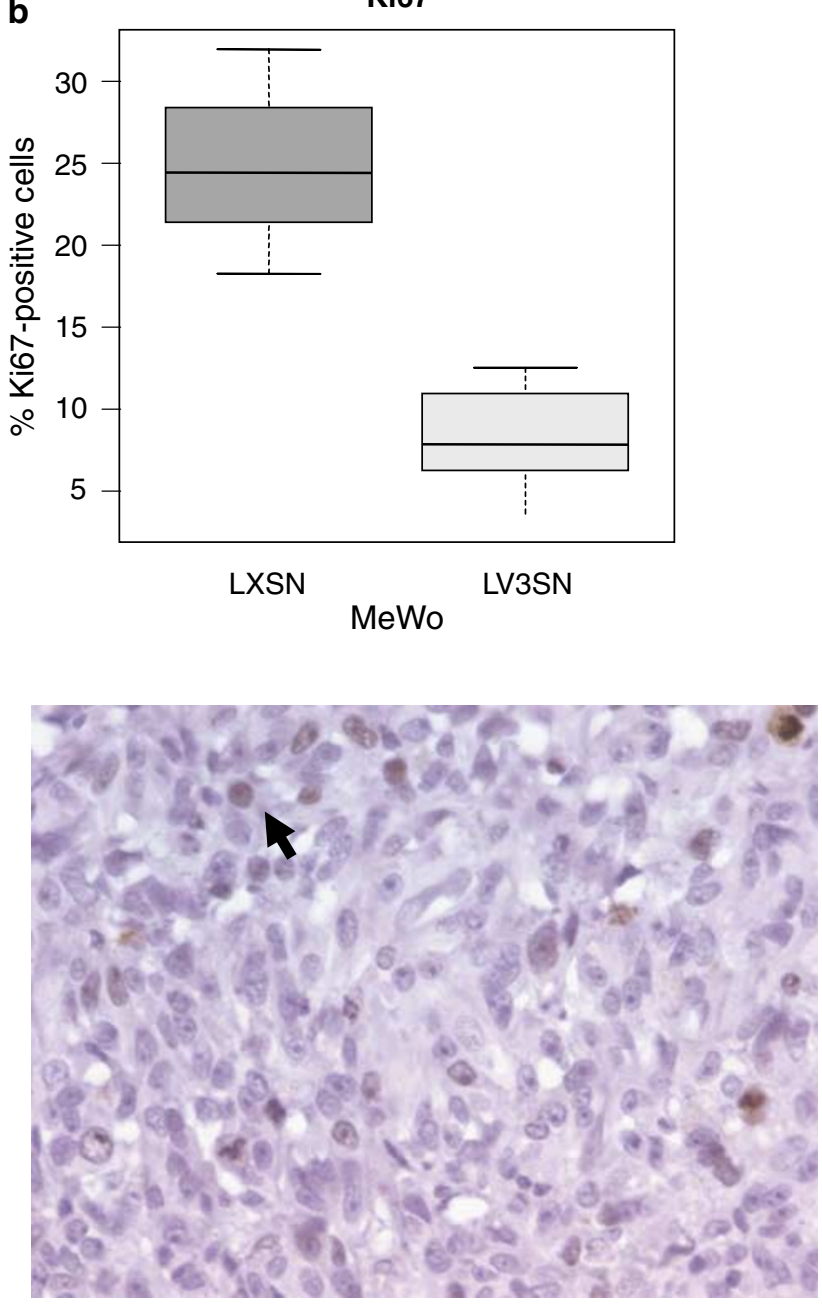

MeWo LV3SN

Figure 1 Proliferative activity in primary tumors arising from LXSN and LV3SN transduced MeWo human melanoma cells. (a) Tumor sections were stained with hematoxylin-eosin and the number of mitoses counted under the microscope. A minimum of eight fields amounting approximately up to 1600 cells were analyzed $(P<0.0001)$. (b) Tumor sections were stained with an antibody recognizing the Ki67 antigen and the number of positive cells counted under the microscope. A minimum of five fields amounting approximately up to 1000 cells were analyzed $(P<0.0001)$. (c) Image from Ki67 positive cells in MeWo LXSN and MeWo LV3SN-derived tumors. A representative positive cell is marked by an arrow. Magnification: $\times 200$.

the difference was not statistically significant $(P=0.1)$.

\section{Histological Characterization of LXSN and LV3SN-Derived Tumors}

As versican is a component of the extracellular matrix, we wanted to analyze whether LXSN and LV3SN tumors show any significant difference in this and other related molecules. As expected, versican is detected only in LV3SN-tumors, whereas LXSN tumors do not produce any significant amount of this molecule (Figure 4) since MeWo cells do not produce any versican isoform in vitro. ${ }^{8,27}$ Furthermore, we analyzed the production of hyaluronan in these tumors. As shown in Figure
5, hyaluronan is heterogeneously distributed inside the tumors, the peripheral areas of the tumors being usually richer in hyaluronan than the inside areas. Hyaluronan was also distributed in bundles or surrounding nests of cells (Figure 5e and f). In all the cases, a higher amount of hyaluronan was produced by LV3SN tumors. Nevertheless, when looking at the expression of the hyaluronan receptor, CD44, there were no differences in staining intensity or intratumoral localization between LXSN and LV3SN tumors (Figure $5 \mathrm{~g}$ and $\mathrm{h}$ ).

Another possibility to explain the delayed growth of LV3SN tumors was vascularization of the tumors. The vessels were immunohistochemically stained by antibodies against the endothelial marker CD31. To quantitate this trait, the Chalkley counting procedure was applied and no significant 

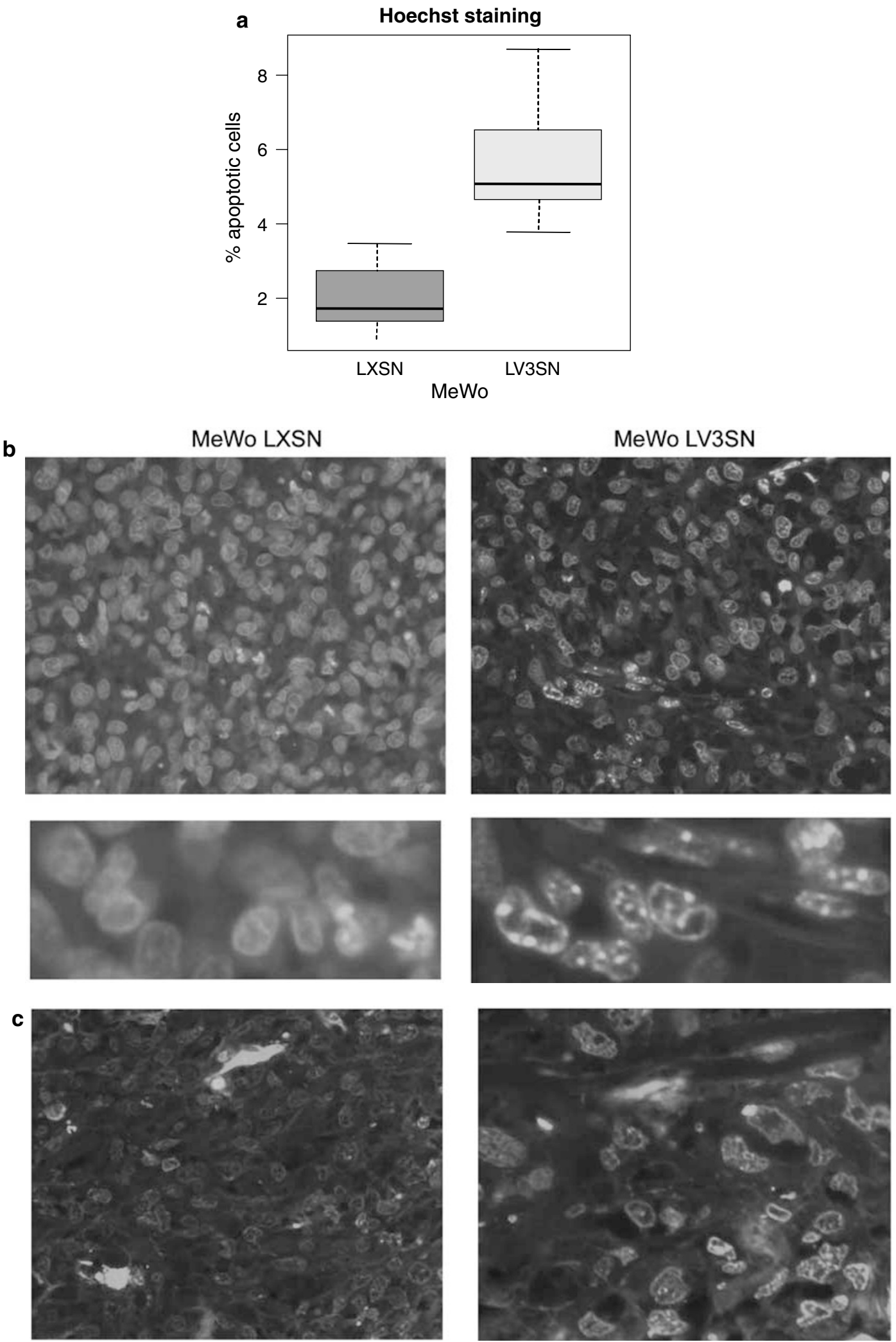

Figure 2 Apoptotic activity in primary tumors arising from LXSN and LV3SN transduced MeWo human melanoma cells. (a) Tumor sections were stained with Hoechst 33342 and the number of apoptotic cells counted under the microscope. A minimum of five fields amounting approximately up to 1000 cells were analyzed $(P<0.001)$. (b) Image from MeWo LXSN and MeWo LV3SN-derived tumors stained with the nuclear staining Hoechst 33342. Magnification: $\times 400$ (c) TUNEL assay from MeWo LXSN and MeWo LV3SN-derived tumors. Magnification: $\times 400$. 


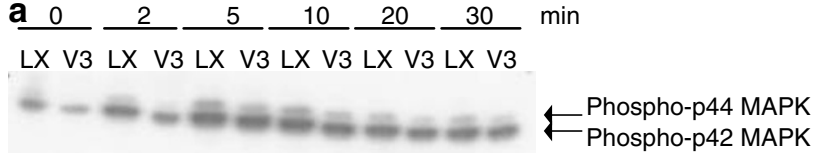

b $0 \quad 2-5 \quad 10 \quad 20 \quad 30 \quad \min$

LX V3 LX V3 LX V3 LX V3 LX V3 LX V3

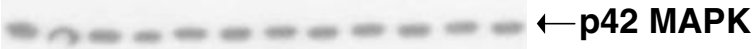

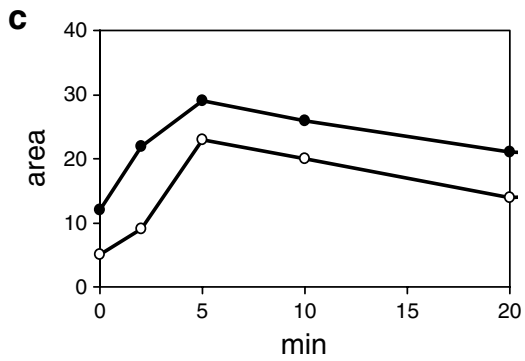

Figure 3 MAPK activation in LXSN and LV3SN transduced MeWo human melanoma cells treated with EGF. Subconfluent cells were treated with $25 \mathrm{ng} / \mathrm{ml}$ EGF in serum-free medium for the indicated times. After the treatment, cell extracts were prepared and the (a) phosphorylated and (b) total forms of MAPK were visualized by Western blot as described in Materials and methods. (c) Densitometric analysis of the total area of the phosphorylated MAPK from LXSN (O) and LV3SN ( $\bigcirc$ ) transduced MeWo cells.

differences were observed ( $P>0.05$; Figure 6). Other molecules that did not show significant expression changes over the tumor type were the $\alpha \nu$ and $\beta 1$ integrin subunits, as assayed with the 17E6 (Figure 6) and P4C10 (not shown) monoclonal antibodies, respectively, and the metalloproteinases MMP-2 (Figure 6), MMP-9 and MT1-MMP (not shown).

\section{Metastatic Potential of V3-Overexpressing Melanoma Cells}

The appearance of spontaneous metastasis was analyzed for MeWo LXSN and MeWo LV3SN human melanoma cells, and CML10c2 LXSN and LV3SN canine melanoma cells. Similarly to MeWo cells, the CML-10c2 cell line lacks endogenous V0 and V1 versican isoforms, and it has a similar delay in in vitro growth rate and latency period of the V3overexpressing tumors. ${ }^{17}$ After surgically excising the primary tumors, mice were maintained until appearance of symptoms indicating spontaneous metastasis. Mice were euthanized and the necropsy performed to identify the location of secondary tumors and their histological characterization.

As shown in Table 2, only LV3SN cells were able to originate lung metastasis in $50 \%$ of the animals for MeWo and 33\% of the animals for CML-10c2 cell lines. No metastasis were found in LXSN-injected animals. Secondary tumors were excised and found to be histologically compatible with melanoma (Figure 7).
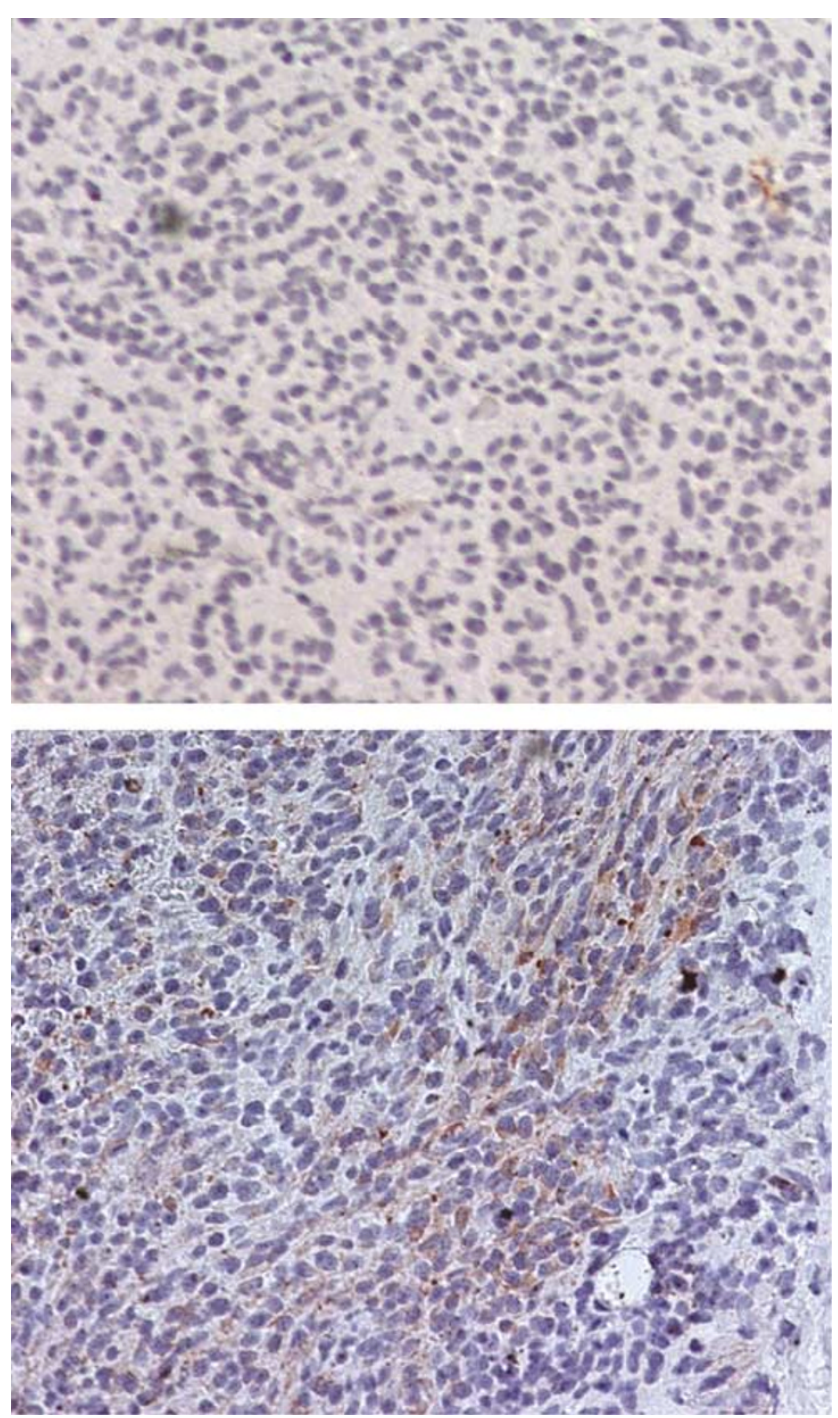

Figure 4 Versican expression in primary tumors derived from LXSN (top) and LV3SN (bottom) MeWo melanoma cells. Sections from tumors were stained with the antibody against versican raised in our laboratory as described in Materials and methods.

\section{Discussion}

In our previous work, we had demonstrated that overexpression of the short V3 isoform of versican was able to alter melanoma cell behavior, counteracting the proliferative and antiadhesive actions of the large V0 and V1 isoforms. This effect was also observed in vivo, since tumors arising in mice from LV3SN cells grew slower than control tumors. ${ }^{17}$ In the present work, we have characterized the primary tumors, as well as addressed the question whether the overexpression of versican V3 could also alter the appearance of spontaneous metastasis.

The characterization of the primary melanoma tumors showed a lower mitotic rate and a lower Ki67-positivity, and an increase in the number of apoptotic cells in LV3SN compared to LXSN tumors. 

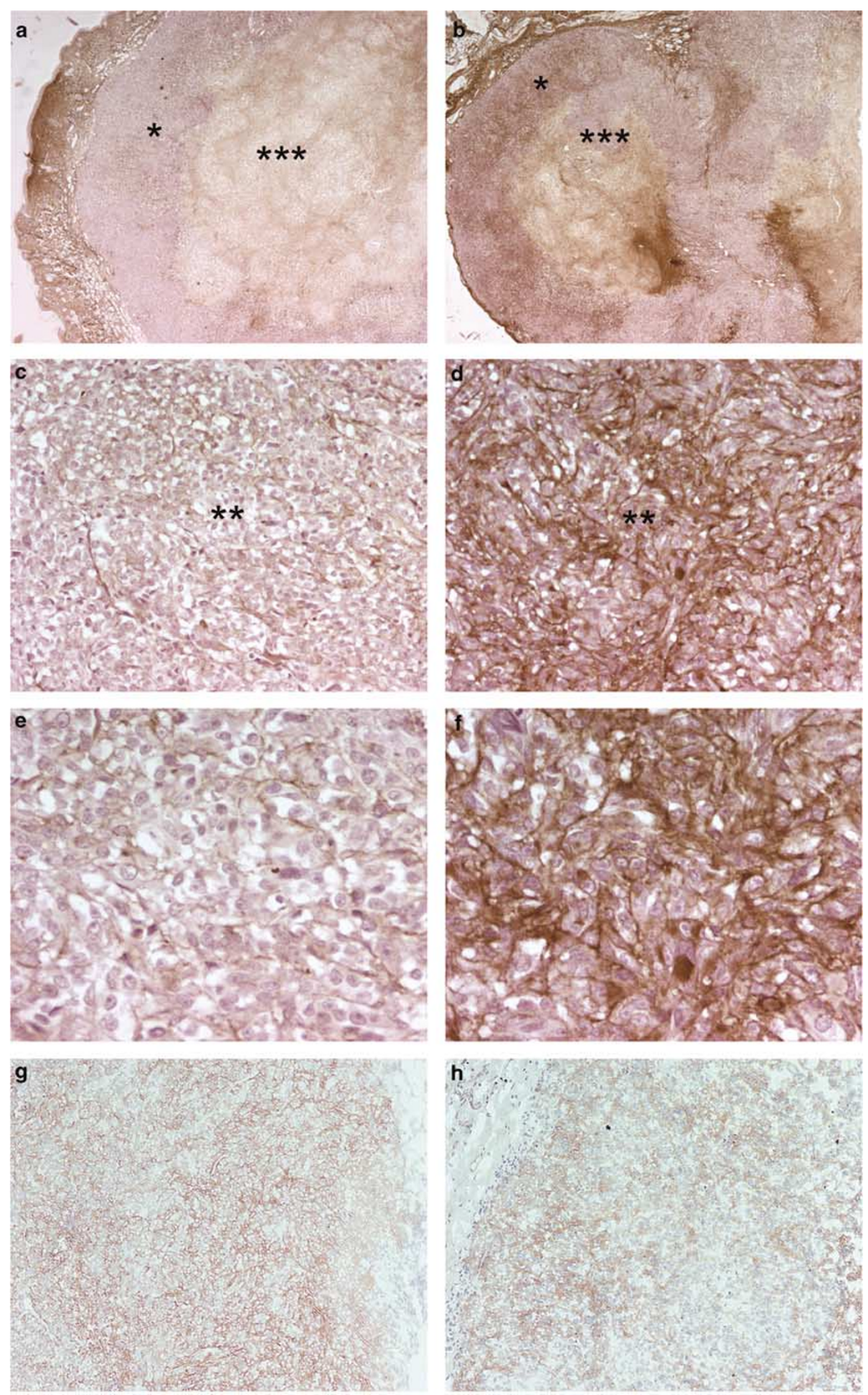

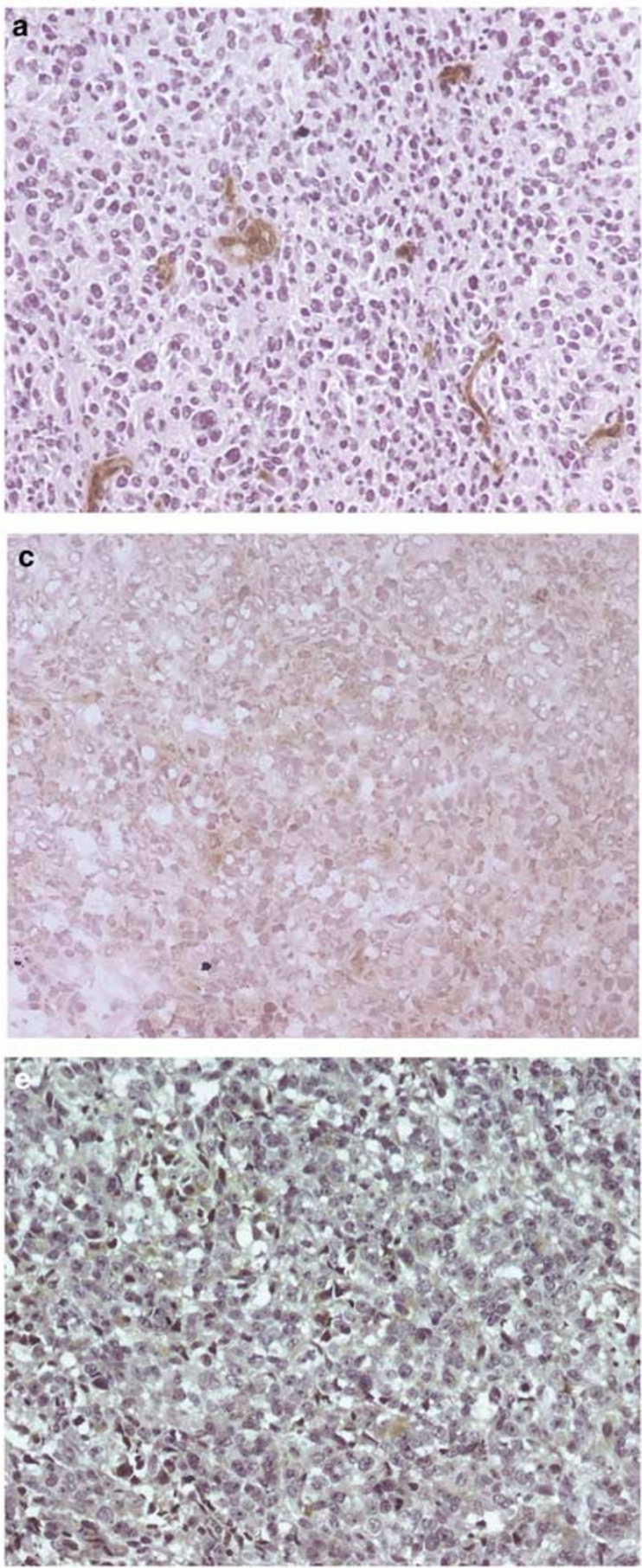

MeWo LXSN

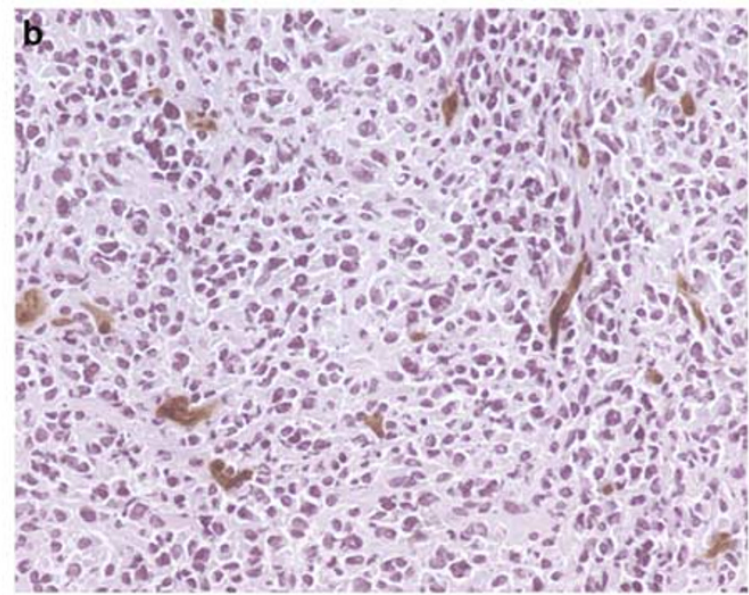

CD31

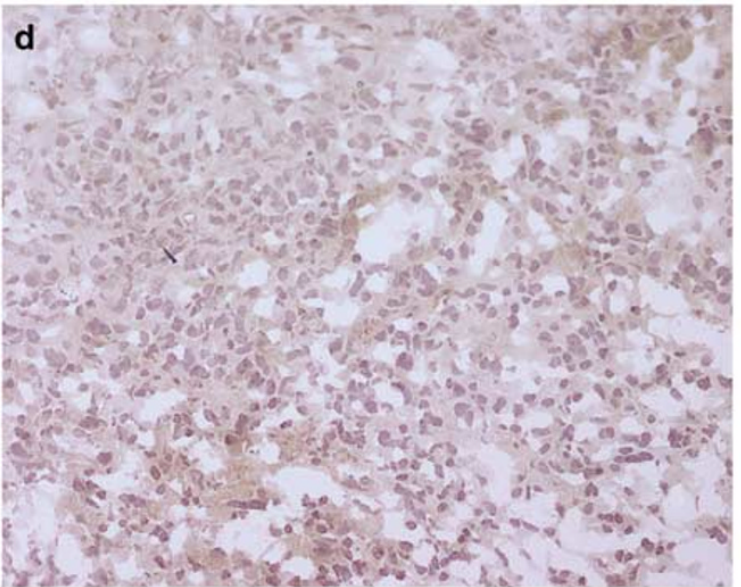

$\alpha \mathrm{V}$

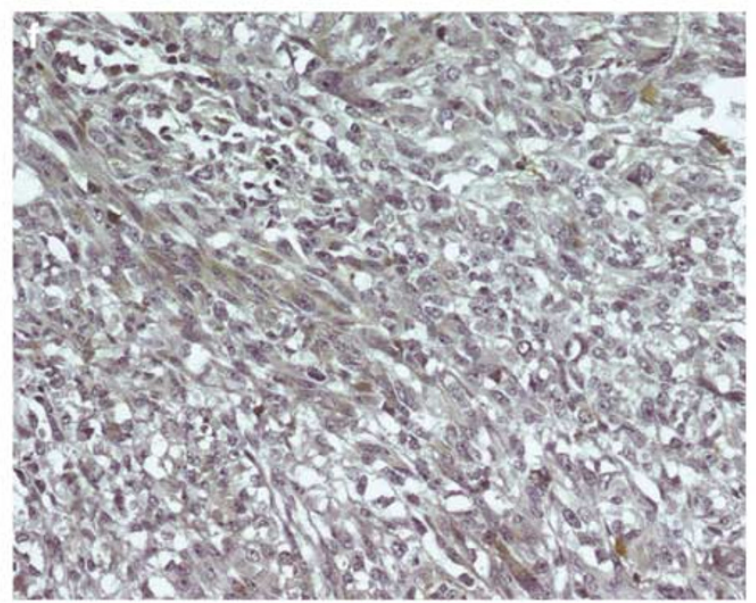

MMP-2

Figure 6 CD31, $\alpha v$ integrin and MMP-2 expression in primary tumors derived from LXSN and LV3SN MeWo melanoma cells. Sections from tumors were stained with anti-CD31 antibodies to visualize tumor vessels (a, b), the 17E6 antibody for $\alpha v$ integrin (c, d) and antiMMP-2 antibody (e, f) as described in Materials and methods. MeWo LXSN (a, c, e), MeWo LV3SN (b, d, f). Magnification: $\times 200$.

Figure 5 Hyaluronan and CD44 expression in primary tumors derived from LXSN and LV3SN MeWo melanoma cells. (a-f) Sections from tumors were stained with bHABP to visualize hyaluronan: $\star$ represents the area magnified in pictures (c) and (d); region labeled as $\star \star$ represents the area magnified in pictures (e) and (f); $\star \star \star$ is the necrotic central area of the tumors. (g-h) Sections from tumors were stained with a monoclonal antibody specific for CD44. MeWo LXSN (a, c, e, g), MeWo LV3SN (b, d, f, h). Magnifications: $\times 20$ (a, b), $\times 200(\mathbf{c}, \mathbf{d}), \times 400(\mathbf{e}, \mathbf{f})$ and $\times 100(\mathbf{g}, \mathbf{h})$. 
Thus, our results indicate that their lower growth rate is due to a dual mechanism: a lower proliferative index as well as an increase in the apoptotic rate. The effect of different versican constructs on tumorigenesis seems to be highly dependent on the versican combined domains as well as on the tumor type. Thus, it has been described that G1-overexpressing sarcoma cells formed larger tumors than the control counterpart probably through a hyaluronan-mediated mechanism. ${ }^{28}$ A growth-promoting effect mediated by an increase in angiogenesis has been described in tumors originated from astrocytoma cells transfected with the G3 domain of versican. ${ }^{29}$ Our V3 construct (composed by the G1 and G3 domains) has the opposite effect than the isolated G1 or G3 domains on

Table 2 Presence of metastasis in lungs of LV3SN-tumors carrying mice

\section{Cell line}

Lung metastasis

\begin{tabular}{ll}
\hline MeWo LXSN & $0 / 4$ \\
MeWo LV3SN & $2 / 4$ \\
CML10c2 LXSN & $0 / 6$ \\
CML10c2 LV3SN & $2 / 6$ \\
\hline
\end{tabular}

Frequency of the appearance of lung metastasis in mice after exeresis of the human melanoma MeWo and canine melanoma CML-10c2 primary tumors. tumorigenesis. Thus, it is clear from these results that different combinations of versican domains will give different biological effects.

Curiously, overexpression of the V3 isoform (G1-

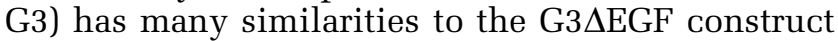
reported by $\mathrm{Wu}$ et $a{ }^{25,30}$ a G3 domain with a deletion of the two EGF-like repeats. In both cases, overexpressing cells grow slower, have a lower tumorigenic potential in nude mice, and display a higher apoptotic rate. It looks like lack of the EGFlike motifs may have the same effect that the presence of G1 plus the entire G3 domain (ie including the EGF-like motifs). Nevertheless, the mechanism underlying the biological effects may be quite different, since we have found an intrinsic difference in cell-cycle rate, whereas an effect on endogenous versican secretion and on integrin expression and activity have been reported as the explanation for the G3 $\Delta \mathrm{EGF}$ construct. ${ }^{25,30,31}$ This is not our case, since neither the amount of endogenous versican changes, ${ }^{17}$ nor we could find any change in $\beta 1$ integrin levels (results not shown).

Our results show a close relationship regarding the lower proliferative ability of LV3SN MeWo cells between in vitro and in vivo results. When analyzing the mechanism to explain this behavior, we have looked at the involvement of the EGF-like domains of the C-terminus of V3, since it has been suggested that

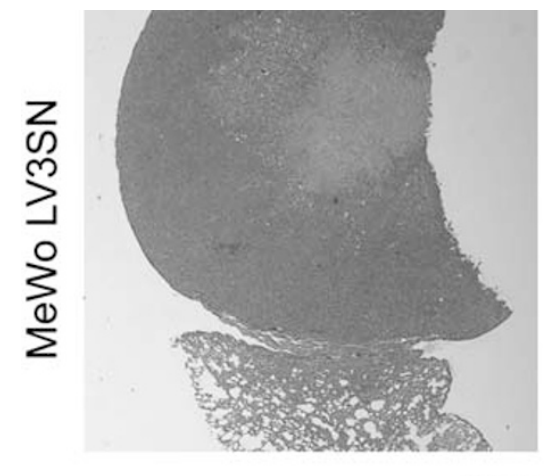

$20 x$

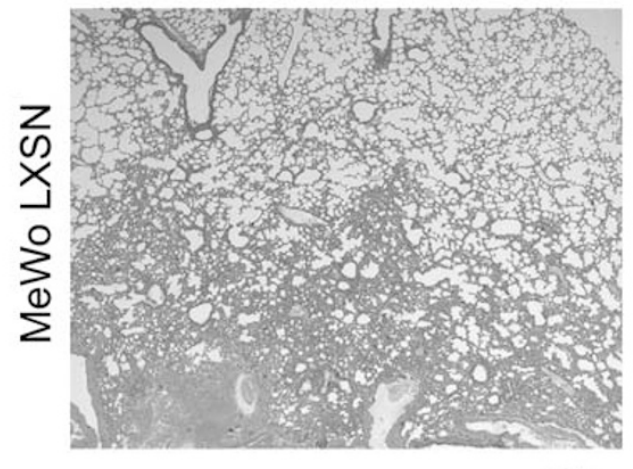

$20 x$

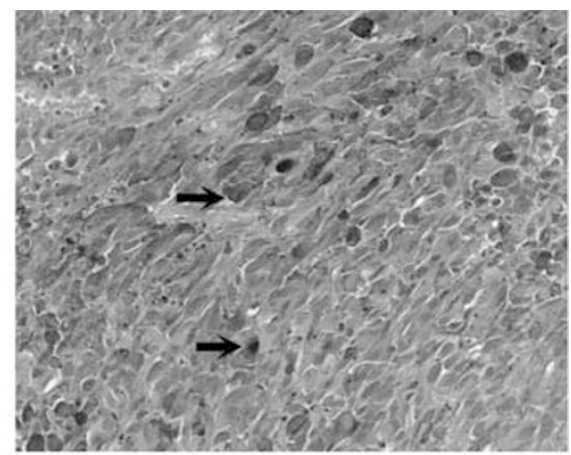

$200 x$

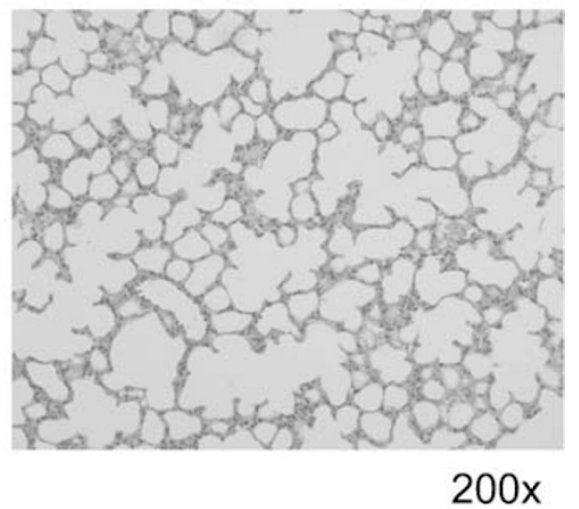

Figure 7 Presence of metastasis in lungs of LV3SN-tumors carrying mice. Histological characterization of secondary tumors in MeWo LXSN mice (no secondary tumors, normal lung tissue) and MeWo LV3SN mice (lung metastasis, the presence of melanin is indicated by arrows). 
those domains could be involved in the cellular response to versican. ${ }^{25,30}$ We have treated our melanoma cells with EGF and looked at the downstream transduction pathway by analyzing the activation of MAPK. As expected, V3-overexpressing melanoma cells had a delayed response to EGF, probably due to the competition of the EGF-like subdomains for binding to the EGF receptor. Moreover, a higher phosphorylation state of MAPK is observed in LXSN MeWo cells in basal conditions. It has been described that the MAPK pathway is often activated in melanoma cells. ${ }^{32-34}$ Thus, interference with mitogenic pathways, such as those triggered by EGF or other related growth factors, may cause the growth inhibition observed in LV3SN MeWo melanoma cells. In our previous report, we had shown that a higher level of the cdk inhibitor p21 can be found in LV3SN cells, as well as a delay in the cell cycle. ${ }^{17}$

It is increasingly accepted that tumor progression is facilitated by changes in the extracellular matrix,$^{35}$ and even that the microenvironment may initiate the oncogenic conversion, ${ }^{36}$ so we characterized the expression of molecules related with versican laid by these tumors. Furthermore, it has been reported that V3 isoform overexpression increases the expression of extracellular tropoelastin and the formation of elastic fibers in smooth muscle cells. ${ }^{37}$ As expected, LV3SN tumors stained positively for versican, whereas LXSN tumors were negative, since MeWo cells do not produce any of the versican isoforms in vitro. ${ }^{27}$ Versican expression in LV3SN tumors was quite intense although heterogeneous, indicating a catabolism and/or redistribution of the molecule inside the tumor. As it has been widely described that versican binds to hyaluronan forming a complex that interacts with the cell through the hyaluronan receptor CD44, we aimed to see whether any of these components were altered in LV3SN tumors, thus explaining the different behavior of these cells. Hyaluronan content was higher in LV3SN tumors, whereas CD44 was not altered in this situation. The intratumoral distribution of hyaluronan was not homogeneous, but it appeared to make bundles, being more abundant in the periphery of the tumor and associated to tumor stroma. This was an unexpected result since hyaluronan content has been described as an indicator of malignancy in several tumor types. ${ }^{38-45}$ In vitro, hyaluronan has been unequivocally related to melanoma proliferation and migration through a CD44-mediated mechanism. ${ }^{46-49}$ As LV3SN cells proliferate slower than LXSN cells, a mechanism independent of HA should be the responsible for this action, as we have suggested above. The balance between both effects in a given situation must define the final behavior of transduced cells. On the other hand, our previous in vitro results had shown that there was no difference between hyaluronan production in cultured LXSN vs LV3SN melanoma cells, ${ }^{17}$ raising the possibility that V3-overexpressing tumor cells have a direct or indirect positive effect on the hyaluronan synthesis by nontumoral cells, as fibroblasts or inflammatory cells from the stroma. It has been previously described that melanoma cells may increase hyaluronan production by stromal cells in the tumor ${ }^{50,51}$ and the presence of V3 may modify that influence. Other possible causes that affect tumor progression as vascularization (assessed as number of tumoral vessels and integrins as $\alpha v$ ), or metalloproteinase expression were unchanged in LV3SN vs LXSN tumors.

On the other hand, our results show an increased apoptosis rate in LV3SN tumors. Although HA has been generally described as a survival agent, a proapoptotic mechanism should be triggered by the presence of the V3 isoform. This mechanism is presently unknown. One simple possibility is that V3 interferes with the interaction between hyaluronan and CD44, blocking the apoptotic activity of the polysaccharide. In this regard, compounds able to compete with hyaluronan in its interaction with CD44, have been described as inducers of apoptosis, such as HA oligomers or soluble CD44..$^{52,53}$ In these cases, the effect of such blockers is a direct competitive action at the binding site, whereas in the case of V3, it may be an indirect action by modifying the structure of the extracellular complexes containing HA. It may be a similar case to that described for BH-P, a peptide containing three HA-binding motifs (the same motif found in hyaladherins), which induces apoptosis in MDA435 and B16 melanoma cells. ${ }^{54}$ Another possibility would be a proapoptotic mechanism of V3 independent of its interaction with HA, similarly to the above mentioned mechanism to explain the effects on proliferation. The apoptotic rate detected in LV3SN tumors is higher than that observed in cell culture, where a very low percentage of dead cells are found. This result may be explained by a different structure of the HA-containing extracellular complexes in tumors, where V3 secreted by melanoma cells should be entrapped into these tridimensional matrices, whereas these structures may be different in vitro. Another possibility would be an indirect effect of $\mathrm{V} 3$ overexpression in vivo, maybe mediated by the stroma present in tumors. It has to be noted that those experiments were performed in the absence of any apoptosis inducer, being related to the basal apoptotic rate of control and LV3SN-derived tumors. Other authors have reported an increased resistance to several apoptotic effectors in G1-overexpressing sarcoma cells, ${ }^{28} \mathrm{~V} 1$ overexpressing fibroblasts, ${ }^{55}$ or a G3 and a miniversican gene in astrocytoma cells. ${ }^{56}$

An important result was obtained when the same mice that hosted the primary tumors were checked for the appearance of metastasis. Primary tumors were excised, and mice were left until symptoms of malignancy were detected. At this stage, mice were euthanized and necropsies were performed. Only mice harboring LV3SN tumors suffered from lung metastasis, whereas any of the LXSN animals 
presented this kind of lesions. This result is reinforced by a parallel experiment performed with CML-10c2 canine melanoma cells ${ }^{17}$ which gave the same result, with no metastasis in LXSN-injected animals and $33 \%$ (2/6 animals) of LV3SN-injected mice presenting lung metastasis. A possible mechanism is the higher production of hyaluronan in LV3SN tumors, which is also observed in tumors arising from CML10c2 cells (not shown). Our previous results had shown that LV3SN cells are able to migrate better on hyaluronan than their control counterparts ${ }^{17}$ and hyaluronan production has been linked to the appearance of metastasis derived from melanoma. ${ }^{46,47,49}$

In conclusion, our results show that V3-overexpression reduces melanoma tumor growth rate by altering the proliferative and apoptotic abilities of tumor cells, but without changing other aspects of the tumor, as vascularization or metalloproteinase production. In contrast, V3 overexpression favors the appearance of secondary tumors probably linked to a higher hyaluronan production by stromal or inflammatory cells, which in turn would enhance migration of melanoma cells outside the tumor.

\section{Acknowledgements}

We thank Dr FX Real (IMIM, Barcelona, Spain) and Dr EG MacEwen (University of Wisconsin, WI) for providing the melanoma cell lines, Dr R Vilella (Hospital Clinic, Barcelona, Spain) for providing the anti-CD44 antibody, and Ms Anna Vilalta for her excellent technical assistance. We thank Ms Kathy Braun (Dr Wight laboratory) for providing the V3 cells. We are especially thankful to Dr J Gil and Dr E Castaño (Faculty of Medicine, Universitat de Barcelona, Spain) for their help with analytical techniques. This work was supported by Grant SAF2003-08750 (to AB) and SAF2002-87 (to AF) from the Ministerio de Ciencia y Tecnologia, Grant 2001SGR00193 from the Generalitat de Catalunya (to $\mathrm{AB}$ ) and NIH Grant \# 18645 (to TNW). DH, CD and MJD were supported by fellowships from UAB Generalitat de Catalunya and the Spanish Ministerio de Educaciòn, respectively. Part of the funding was financed by the FEDER program from the European Union.

\section{Duality of interest}

None declared.

\section{References}

$1 \mathrm{Wu}$ YJ, La Pierre DP, Wu J, et al. The interaction of versican with its binding partners. Cell Res 2005; 15:483-494.

2 Yamaguchi Y. Lecticans: organizers of the brain extracellular matrix. Cell Mol Life Sci 2000;57:276-289.
3 Wight TN. Versican: a versatile extracellular matrix proteoglycan in cell biology. Curr Opinion Cell Biol 2002;14:617-623.

4 Dours-Zimmermann MT, Zimmermann DR. A novel glycosaminoglycan attachment domain identified in two alternative splice variants of human versican. J Biol Chem 1994;269:32992-32998.

5 Iozzo RV. Matrix proteoglycans: from molecular design to cellular function. Annu Rev Biochem 1998;67: 609-652.

6 Matsumoto K, Shionyu M, Go M, et al. Distinct interaction of versican/PG-M with hyaluronan and link protein. J Biol Chem 2003;278:41205-41212.

7 Ito K, Shinomura T, Zako M, et al. Multiple forms of mouse PG-M, a large chondroitin sulfate proteoglycan generated by alternative splicing. J Biol Chem 1995; 270:958-965.

8 Touab M, Villena J, Barranco C, et al. Versican is differentially expressed in human melanoma and may play a role in tumor development. Am J Pathol 2002;160:549-557.

9 Touab M, Arumi-Uria M, Barranco C, et al. Expression of the proteoglycans versican and mel-CSPG in dysplastic nevi. Am J Clin Pathol 2003;119:587-593.

10 Ricciardelli C, Mayne K, Sykes PJ, et al. Elevated levels of versican but not decorin predict disease progression in early-stage prostate cancer. Clin Cancer Res 1998;4:963-971.

11 Sakko AJ, Ricciardelli C, Mayne K, et al. Versican accumulation in human prostatic fibroblast cultures is enhanced by prostate cancer cell-derived transforming growth factor beta1. Cancer Res 2001;61:926-930.

12 Sakko AJ, Ricciardelli C, Mayne K, et al. Modulation of prostate cancer cell attachment to matrix by versican. Cancer Res 2003;63:4786-4791.

13 Nara Y, Kato Y, Torii Y, et al. Immunohistochemical localization of extracellular matrix components in human breast tumours with special reference to PGM/versican. Histochem J 1997;29:21-30.

14 Ricciardelli C, Brooks JH, Suwiwat S, et al. Regulation of stromal versican expression by breast cancer cells and importance to relapse-free survival in patients with node-negative primary breast cancer. Clin Cancer Res 2002;8:1054-1060.

15 Suwiwat S, Ricciardelli C, Tammi R, et al. Expression of extracellular matrix components versican, chondroitin sulfate, tenascin, and hyaluronan, and their association with disease outcome in nodenegative breast cancer. Clin Cancer Res 2004;10: 2491-2498.

16 Isogai Z, Shinomura T, Yamakawa N, et al. 2B1 antigen characteristically expressed on extracellular matrices of human malignant tumors is a large chondroitin sulfate proteoglycan, PG-M/versican. Cancer Res 1996;56:3902-3908.

17 Serra M, Miquel L, Domenzain C, et al. V3 versican isoform expression alters the phenotype of melanoma cells and their tumorigenic potential. Int J Cancer 2005;114:879-886.

18 Lemire JM, Merrilees MJ, Braun KR, et al. Overexpression of the V3 variant of versican alters arterial smooth muscle cell adhesion, migration, and proliferation in vitro. J Cell Physiol 2002;190:38-45.

19 Houghton AN, Real FX, Davis LJ, et al. Phenotypic heterogeneity of melanoma. Relation to the differentiation program of melanoma cells. J Exp Med 1987; 165:812-829. 
20 Wolfe LG, Oliver JL, Smith BB, et al. Biologic characterization of canine melanoma cell lines. Am J Vet Res 1987;48:1642-1648.

21 Serra M, Pastor J, Domenzain C, et al. Effect of transforming growth factor-beta1, insulin-like growth factor-I, and hepatocyte growth factor on proteoglycan production and regulation in canine melanoma cell lines. Am J Vet Res 2002;63:1151-1158.

22 Fischer JW, Kinsella MG, Hasenstab D, et al. Cellmediated transfer of proteoglycan genes. Methods Mol Biol 2001;171:261-269.

23 Laemmli UK. Cleavage of structural proteins during the assembly of the head of bacteriophage T4. Nature 1970;227:680-685.

24 Chalkley H. Methods for the quantitative morphological analysis of tissues. J Natl Cancer Inst 1943;4:47-53.

$25 \mathrm{Wu}$ Y, Zhang Y, Cao L, et al. Identification of the motif in versican G3 domain that plays a dominant-negative effect on astrocytoma cell proliferation through inhibiting versican secretion and binding. J Biol Chem 2001;276:14178-14186.

26 Zhang Y, Wu Y, Cao L, et al. Versican modulates embryonic chondrocyte morphology via the epidermal growth factor-like motifs in G3. Exp Cell Res 2001; 263:33-42.

27 Domenzain C, Docampo MJ, Serra M, et al. Differential expression of versican isoforms is a component of the human melanoma cell differentiation process. Biochim Biophys Acta 2003;1642:107-114.

28 Cattaruzza S, Schiappacassi M, Kimata K, et al. The globular domains of PG-M/versican modulate the proliferation-apoptosis equilibrium and invasive capabilities of tumor cells. FASEB J 2004;18:779-781.

29 Zheng PS, Wen J, Ang LC, et al. Versican/PG-M G3 domain promotes tumor growth and angiogenesis. FASEB J 2004;18:754-756.

$30 \mathrm{Wu} \mathrm{Y}$, Chen L, Cao L, et al. Overexpression of the C-terminal PG-M/versican domain impairs growth of tumor cells by intervening in the interaction between epidermal growth factor receptor and beta1-integrin. J Cell Sci 2004;117:2227-2237.

$31 \mathrm{Wu} \mathrm{Y}$, Chen L, Zheng PS, et al. beta 1-Integrinmediated glioma cell adhesion and free radicalinduced apoptosis are regulated by binding to a C-terminal domain of PG-M/versican. J Biol Chem 2002;277:12294-12301.

32 Cohen C, Zavala-Pompa A, Sequeira JH, et al. Mitogenactived protein kinase activation is an early event in melanoma progression. Clin Cancer Res 2002;8: 3728-3733.

33 Smalley KS. A pivotal role for ERK in the oncogenic behaviour of malignant melanoma? Int J Cancer 2003;104:527-532.

34 Meier F, Schittek B, Busch S, et al. The RAS/RAF/ MEK/ERK and PI3K/AKT signaling pathways present molecular targets for the effective treatment of advanced melanoma. Front Biosci 2005;10: 2986-3001.

35 Tlsty TD, Coussens LM. Tumor Stroma and Regulation of Cancer Development. Ann Rev Pathol 2006;1: 119-150.

36 Comoglio PM, Trusolino L. Cancer: the matrix is now in control. Nat Med 2005;11:1156-1159.

37 Merrilees MJ, Lemire JM, Fischer JW, et al. Retrovirally mediated overexpression of versican V3 by arterial smooth muscle cells induces tropoelastin synthesis and elastic fiber formation in vitro and in neointima after vascular injury. Circulat Res 2002;90: 481-487.

38 Pauli BU, Knudson W. Tumor invasion: a consequence of destructive and compositional matrix alterations. Hum Pathol 1988;19:628-639.

39 Knudson W. Tumor-associated hyaluronan. Providing an extracellular matrix that facilitates invasion. Am J Pathol 1996;148:1721-1726.

40 Toole BP, Wight TN, Tammi MI. Hyaluronan-cell interactions in cancer and vascular disease. J Biol Chem 2002;277:4593-4596.

41 Toole BP, Hascall VC. Hyaluronan and tumor growth. Am J Pathol 2002;161:745-747.

42 Toole BP. Hyaluronan promotes the malignant phenotype. Glycobiology 2002;12:37R-42R.

43 Zoltan-Jones A, Huang L, Ghatak S, et al. Elevated hyaluronan production induces mesenchymal and transformed properties in epithelial cells. J Biol Chem 2003;278:45801-45810.

44 Ward JA, Huang L, Guo $\mathrm{H}$, et al. Perturbation of hyaluronan interactions inhibits malignant properties of glioma cells. Am J Pathol 2003;162:1403-1409.

45 Toole BP. Hyaluronan: from extracellular glue to pericellular cue. Nat Rev Cancer 2004;4:528-539.

46 Guo Y, Ma J, Wang J, et al. Inhibition of human melanoma growth and metastasis in vivo by anti-CD44 monoclonal antibody. Cancer Res 1994;54: 1561-1565.

47 Goebeler M, Kaufmann D, Brocker EB, et al. Migration of highly aggressive melanoma cells on hyaluronic acid is associated with functional changes, increased turnover and shedding of CD44 receptors. J Cell Sci 1996;109(Part 7):1957-1964.

48 Ichikawa T, Itano N, Sawai T, et al. Increased synthesis of hyaluronate enhances motility of human melanoma cells. J Invest Dermatol 1999;113:935-939.

49 Yoshihara S, Kon A, Kudo D, et al. A hyaluronan synthase suppressor, 4-methylumbelliferone, inhibits liver metastasis of melanoma cells. FEBS Lett 2005; 579:2722-2726

50 Edward M, Gillan C, Micha D, et al. Tumour regulation of fibroblast hyaluronan expression: a mechanism to facilitate tumour growth and invasion. Carcinogenesis 2005;26:1215-1223.

51 Luke HJ, Prehm P. Synthesis and shedding of hyaluronan from plasma membranes of human fibroblasts and metastatic and non-metastatic melanoma cells. Biochem J 1999;343(Part 1):71-75.

52 Ghatak S, Misra S, Toole BP. Hyaluronan oligosaccharides inhibit anchorage-independent growth of tumor cells by suppressing the phosphoinositide 3-kinase/ Akt cell survival pathway. J Biol Chem 2002;277: 38013-38020.

53 Peterson RM, Yu Q, Stamenkovic I, et al. Perturbation of hyaluronan interactions by soluble CD44 inhibits growth of murine mammary carcinoma cells in ascites. Am J Pathol 2000;156:2159-2167.

$54 \mathrm{Xu} \mathrm{XM}$, Chen Y, Chen J, et al. A peptide with three hyaluronan binding motifs inhibits tumor growth and induces apoptosis. Cancer Res 2003;63: 5685-5690.

55 Sheng W, Wang G, Wang Y, et al. The roles of versican $\mathrm{V} 1$ and V2 isoforms in cell proliferation and apoptosis. Mol Biol Cell 2005;16:1330-1340.

$56 \mathrm{Wu}$ Y, Wu J, Lee DY, et al. Versican protects cells from oxidative stress-induced apoptosis. Matrix Biol 2005; 24:3-13. 